\title{
Decrease of Nitrergic Innervation in the Esophagus of Patients with Chagas Disease: Correlation with Loss of Interstitial Cells of Cajal
}

\author{
Rodolfo Duarte Nascimento ${ }^{1}$, Patrícia Rocha Martins ${ }^{2}$, Jacqueline Garcia Duarte ${ }^{2}$ and Débora d'Ávi- \\ Ia Reis ${ }^{2 *}$
}

${ }^{1}$ Departamento de Ciências Básicas da Vida, Instituto de Ciências da Vida, Universidade Federal de Juiz de Fora, Brazil

${ }^{2}$ Departamento de Morfologia, Instituto de Ciências Biológicas, Universidade Federal de Minas Gerais, Brazil

*Corresponding author: Débora d'Ávila Reis, Departamento de Morfologia, Instituto de Ciências Biológicas, Universidade Federal de Minas Gerais, Av. Presidente Antônio Carlos, 6627, Pampulha, CEP 31270-901, Minas Gerais, Brazil, Tel: +5531-3409-2820, E-mail: debsdavila@gmail.com

\begin{abstract}
The pathogenesis of megaesophagus in chronic Chagas disease, which is caused by infection with the parasite Trypanosoma cruzi is compelling. Individuals with megaesophagus often present achalasia and disturbances of peristalsis and neuronal loss. Esophageal samples were obtained from $6 T$. cruzi infected individuals with megaesophagus, 6 $T$. cruzi infected individuals without megaesophagus, and 6 noninfected individuals who underwent necropsy procedures. Using one antibody specific for neuronal Nitric Oxide Synthase (nNOS) and another specific for Protein Gene Product 9.5 (PGP-9.5), which is a pan-neuronal marker, we demonstrated the relative area of nitrergic innervation. Additionally, we analysed the area occupied by Interstitial Cells of Cajal (ICCs) with antibody specific anti-CD117. The analyses presented here show that the relative area of nitrergic innervation is reduced in $T$. cruzi infected individuals with megaesophagus. Furthermore, we demonstrated reduced CD117-immunostained areas in the esophagus of $T$. cruzi infected individuals. Statistical analyses revealed a positive correlation between the relative area of nitrergic innervation and the density of ICCs in the same infected individuals. Considering data from the literature, we raised the hypothesis that the loss of nitrergic nerve fibers and ICCs could be view as an interdependent phenomenon occurring in the esophagus of $T$. cruzi infected individuals and that it could contribute to peristalsis disturbances, to achalasia and to megaesophagus development.
\end{abstract}

\section{Keywords}

Chagasic megaesophagus, Denervation, Nitrergic nerve fibers, Interstitial cells of cajal

\section{Introduction}

Chagas disease is caused by the intracellular parasite Trypanosoma cruzi and affects approximately 6-7 millions individuals in Latin America still today [1]. The acute infection displays a variable clinical course, with high parasitemia and a high parasite load within affected tissues. In the chronic phase some patients remain asymptomatic but after a indeterminate time course of infection some of them could present symptoms that reflect cardiac and/or digestive tract involvement [2].

The digestive form of Chagas disease is characterised by dilatation of the Gastrointestinal (GI) tract and the esophagus and colon most often been affected, and may progress to megaesophagus and mega colon, respectively [3]. Individuals with chagasic megaesophagus usually present dysphasia, peristaltic dysfunction and achalasia, and partial or absent lower esophageal sphincter relaxation [4] witch develop in consequence of the denervation $[5,6]$. Structural damage of the Enteric Nervous System (ENS), denervation above $90 \%$ in the myenteric plexus [7], ganglionitis and periganglionitis have been widely described in the digestive form of Chagas disease $[8,9]$. It is well known, however, that motility regulation in the GI tract and lower esophageal sphincter relaxation is influenced not only by neuromediators, as Nitric Oxide (NO), but also by Interstitial Cells of Cajal (ICCs) [10-13]. 
The production of NO by neurons of the ENS, coupled with its transmission to the muscle in the esophagus, is necessary for sphincter relaxation. This process is essential for muscle relaxation during peristalsis and it allows for the passage of gut contents [14,15]. Commonly observed in several regions of the GI tract, the ICCS are responsible for generating and propagating "slow waves" to the muscle layers, constituting the pacemaker system $[16,17]$. This system regulates the membrane potential of smooth muscle cells. When peristaltic activation begins, the electrical activity of the ICCs sets the pace, the frequency and the amplitude of contraction waves. ICCs within the muscle layers have been shown to be in close proximity to varicose nerve fibers and smooth muscle cells and have led to the suggestion that this class of ICCs may be involved in or mediate enteric neurotransmission [18].

Studies in mice have suggested that intramuscular ICCs may play a critical role in NO-dependent neurotransmission in the $\mathrm{Gl}$ tract and the reduction of both have been implicated as cause of dysfunction of the lower esophageal sphincter and esophageal peristalsis in $\mathrm{nNOS}^{-/}$and $\mathrm{ICC}^{-/}$mice $[19,20]$. Decreased nitrergic innervation and loss of ICCs have been observed in idiopathic achalasia and those factors, in conjunction, have been considered to be implicated in such pathological process $[21,22]$. Previous studies of individuals with the digestive form of Chagas disease, have reported a decrease of ICCs density in the esophagus and colon that were associated with megaesophagus and megacolon, respectively $[23,24]$. Other study has demonstrated rel- ative decrease in the number of neurons in colon of chagasic patient with megacolon [25].

Therefore the present study was designed in order to evaluate, in the lower portion of esophagus from $T$. cruzi infected individuals, the relative area of nNOS Immunoreactive (IR) nerve fibers and ICCs density.

\section{Materials and Methods}

\section{Patients and tissue samples}

Esophageal samples were obtained from $6 T$. cruzi infected individuals with megaesophagus, $6 T$. cruzi infected individuals without megaesophagus and 6 noninfected individuals who underwent necropsy procedures at Federal University of Triângulo Mineiro (Uberaba, Minas Gerais, Brazil). The individuals previously lived in Uberaba, MG, Brazil, where the natural transmission of Chagas disease was interrupted more than 30 years ago. Research consent was obtained from family members prior to tissue procurement. Serological tests diagnostic for Chagas disease (ELISA, hemagglutination and immunofluorescent tests) were positive in all study individuals.

The noninfected group was composed of individuals with negative Chagas specific serology. These participants were also from the state of Minas Gerais (average age of $62.5 \pm 20.42$ years) and had an esophagus diameter of $1.4 \pm 0.16 \mathrm{~cm}$. Infected individuals without megaesophagus (average age of $55.5 \pm 11.88$ years) had an esophagus diameter of $1.3 \pm 0.23 \mathrm{~cm}$. Infected individuals with megaesophagus (average age of $52.5 \pm 9$ years) had an esophagus diameter of $3.3 \pm 0.79 \mathrm{~cm}$ (Table 1 ).

Table 1: Study group.

\begin{tabular}{|c|c|c|c|c|}
\hline & Age (years) & $\begin{array}{l}\text { Diameter of the } \\
\text { esophagus }(\mathrm{cm})\end{array}$ & Gender & $\begin{array}{l}\text { Area of PGP } 9.5 \text {-IR nerve } \\
\text { fibers }\left(\mu \mathrm{m}^{2}\right)^{\star}\end{array}$ \\
\hline \multicolumn{5}{|c|}{ Non-infected individuals } \\
\hline E2 & 76 & 1.6 & M & 287 \\
\hline E5 & 54 & 1.4 & $M$ & 229 \\
\hline E17 & 79 & 1.6 & M & 196 \\
\hline HE12-94 & 34 & 1.5 & $M$ & 372 \\
\hline HE83-93 & 85 & 1.2 & M & 328 \\
\hline HE93-93 & 47 & 1.3 & M & 262 \\
\hline \multicolumn{5}{|c|}{ Infected individuals without megaesophagus } \\
\hline & & & & \\
\hline E3 & 49 & 1.1 & $\mathrm{~F}$ & 325 \\
\hline E9 & 47 & 1.3 & $\mathrm{~F}$ & 243 \\
\hline E14 & 70 & 1.7 & M & 250 \\
\hline E4 & 61 & 1.6 & M & 176 \\
\hline E7 & 66 & 1.4 & M & 195 \\
\hline E15 & 40 & 1.2 & M & 197 \\
\hline \multicolumn{5}{|c|}{ Infected individuals with megaesophagus } \\
\hline E12 & 57 & 2.7 & M & 16 \\
\hline HE30-00 & 52 & 4.5 & M & 20 \\
\hline HE45-93 & 53 & 4.1 & M & 18 \\
\hline HE46-01 & 43 & 3.0 & $\mathrm{~F}$ & 24 \\
\hline ML10-86 & 43 & 2.6 & M & 23 \\
\hline HE71-00 & 67 & 2.9 & M & 17 \\
\hline
\end{tabular}

*Analyzed by Nascimento, et al. [5].

Abbreviations: F: Female; M: Male. 
The diagnosis of megaesophagus was established from clinical data reporting esophagus obstruction and from radiological studies. Tissue samples were collected from the lower third of the esophagus far $5 \mathrm{~cm}$ of the cardia (the junction between the stomach and the esophagus). The tissue was processed in $4 \%$ neutral buffered formaldehyde solution and embedded in paraffin for immunohistochemical studies. Subsequently, the esophagus rings were cut into serial $5 \mu \mathrm{m}$ sections and treated with either immunohistochemical or Giemsa staining.

\section{Immunohistochemical analysis}

Paraffin-embedded tissues from chagasic individuals and noninfected individuals were immunostained for ICCs and nerves fibers. Esophagus sections $(5 \mu \mathrm{m}$ thick) were deparaffinised with xylene and dehydrated in graded alcohols. Endogenous peroxide activity was inhibited by incubation with $4 \%$ hydrogen peroxide and $0.05 \mathrm{M}$ sodium azide for 30 minutes. The slides were then incubated in $2 \%$ normal swine serum (SIGMA, MO, USA) in phosphate-buffered saline for 30 minutes and, subsequently, with polyclonal antibodies specific to receptor protein surface tyrosine kinase (c-Kit), anti-CD117 (DAKO, Carpinteria, CA, USA; code A4502, 1:25), PGP 9.5 (DAKO, Carpinteria, CA, USA; code Z5116, 1:50) or anti-nNOS against neuronal nitric oxide synthase (ABCAM, Cambridge, MA, USA; code ab106417, $1: 25)$ and this incubation was followed by a second incubation with peroxidase conjugated rabbit anti-mouse antibodies (DAKO, CA, USA) for $60 \mathrm{~min}$. Peroxidase activity was demonstrated by incubation with 3,3-diaminobenzidine (Sigma) and hydrogen peroxidase for 10 minutes. The slides were counterstained with Gill's haematoxylin (Sigma), dehydrated in graded alcohols and mounted in synthetic mounting media.

\section{Morphometric studies}

A Morphometric analysis of immune-stained areas was performed using an image analysis system (Kontron KS300 version 2.0; Kontron, Port Coquitlam, Canada) on 20 randomly selected fields (total area of 1180 $\times 10^{3} \mu \mathrm{m}^{2}$ ) of the inner muscle layer using one slide per individual. The relative area of nNOS-IR nerve fibers was calculated as follows: nNOS-IR area/PGP 9.5-IR area $x$ 100.

To quantify the distribution of ICCs, we employed immunohistochemistry using an anti-CD117 polyclonal antibody, which also reacts with mast cells [26]. Therefore, to identify or exclude the presence of mast cells, consecutive sections underwent Giemsa staining and those images were captured and analysed.

\section{Statistics}

After normality test, statistical analysis was performed using a one-way Analysis of Variance (ANOVA) and Turkey's Multiple Comparison post-test. A correlation analysis was performed using the Pearson parametric test. The values are expressed as the mean \pm SD (standard deviation) and differences were considered statistically significant at $p<0.05$.

\section{Results}

The inner muscle layer of the esophagus from serologically negative controls demonstrated abundant nNOS-IR nerve fibers (Figure 1A). A similar distribution of nNOS-IR nerve fibers was also observed in the inner muscle layer of the esophagus from infected individuals without megaesophagus (Figure 1B). However, infected individuals with megaesophagus showed a decrease in nNOS-IR nerve fibers density (Figure $1 \mathrm{C}$ ). Morphometric analysis of immunohistochemistry treated tissue sections revealed that individuals infected with megaesophagus have a significant reduction in the relative area of nNOS-IR nerve fibers compared to noninfected individuals, but no significant difference was observed between individuals infected without megaesophagus and the remaining two groups (Figure 2).

To determine the distribution of ICCS, we employed an anti-CD117 polyclonal antibody, which also reacts with mast cells. Therefore, to identify or exclude the presence of mast cells, consecutive sections were prepared and subjected to Giemsa staining (Figure $3 \mathrm{~A}$ and Figure 3B). Within the inner muscular layer, CD117-IR ICCs were observed among the smooth muscle cells and exhibited an elongated shape, oval nuclei and prominent bipolar ramifications, which may or may not be
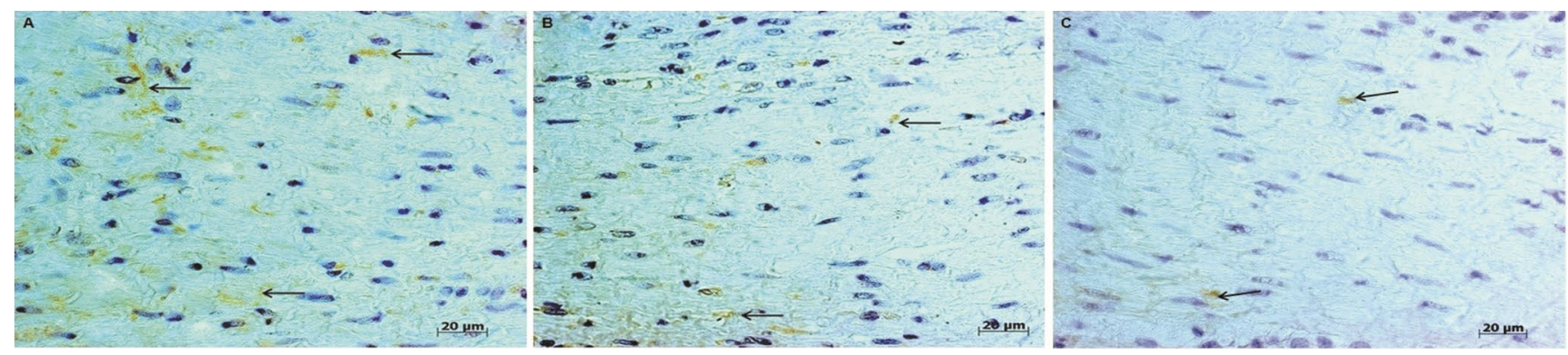

Figure 1: A) Immunohistochemical profile of nNOS-IR nerve fibers (arrows) in the inner muscle layer of esophagus from noninfected individuals; B) Infected individuals without megaesophagus; C) Infected individuals with megaesophagus (Original magnification of 400x). 


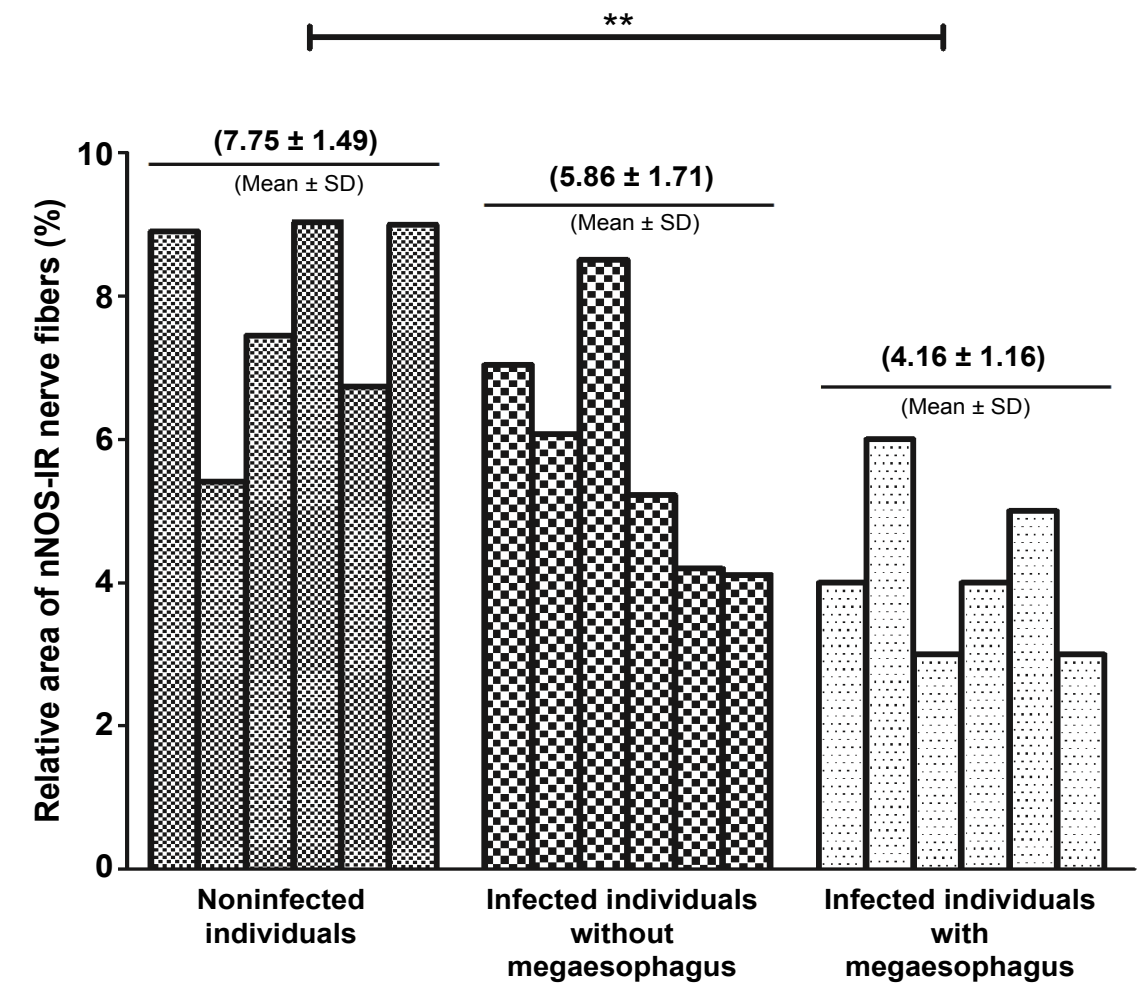

Figure 2: Data from morphometric analysis of relative area of nNOS-IR nerve fibers in the inner muscle layer of esophagus from noninfected individuals, infected individuals with and without megaesophagus. The bars express individual values and the mean \pm SD is presented above each group.

* "Statistically significant differences between the noninfected individuals and the infected individuals with megaesophagus were observed $(p<0.01)$.

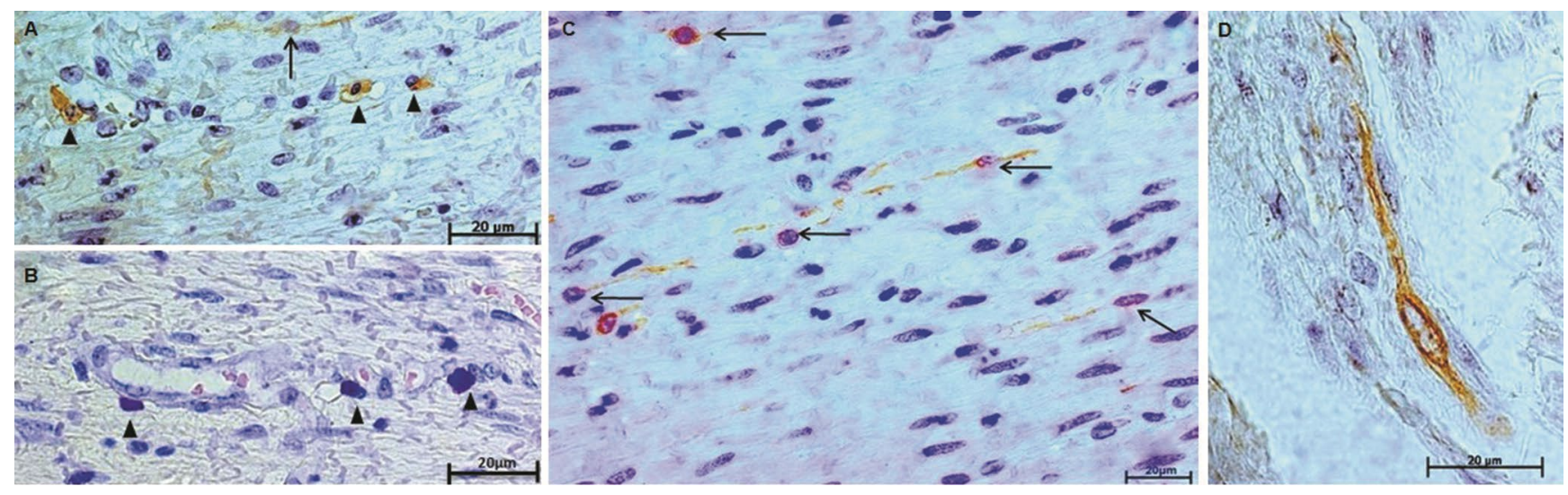

Figure 3: A) ICC (arrow) and mast cell (arrowhead) immunoreactive to CD117 (original magnification of 630x); B) Mast cells observed with giemsa staining (arrowhead; original magnification of 630x); C) Distribution of CD117 ICC-IR in the inner muscle layer of the esophagus from noninfected individuals (arrow; original magnification of 630x); D) Morphological profile of ICC (original magnification of $1000 x$ ).

associated with other ICCs (Figure 3C and Figure 3D). A morphometric analysis revealed an equally significant decrease in the density of CD117-IR ICCs in both groups of individuals infected, with and without megaesophagus (Figure 4).

Furthermore, statistical analyses of the data obtained from infected individuals revealed a positive correlation between the relative area of $\mathrm{nNOS}$-IR nerve fibers and the area of CD117-IR staining ( $r=0.6263$ and $p=0.0293$; Figure 5).

\section{Discussion}

We present a semi-quantitative study of ICCs and of the nNOS-IR nerve fibers density in $T$. cruzi infected individuals with and without megaesophagus. To the best of our knowledge, no previous studies have demonstrated that the distal esophagus of individuals infected with megaesophagus have a decreased relative area of nNOS-IR nerve fibers compared to noninfected individuals. Neural NOS (nNOS) is an enzyme found in neurons supplying the muscle of the gastrointestinal tract. The 


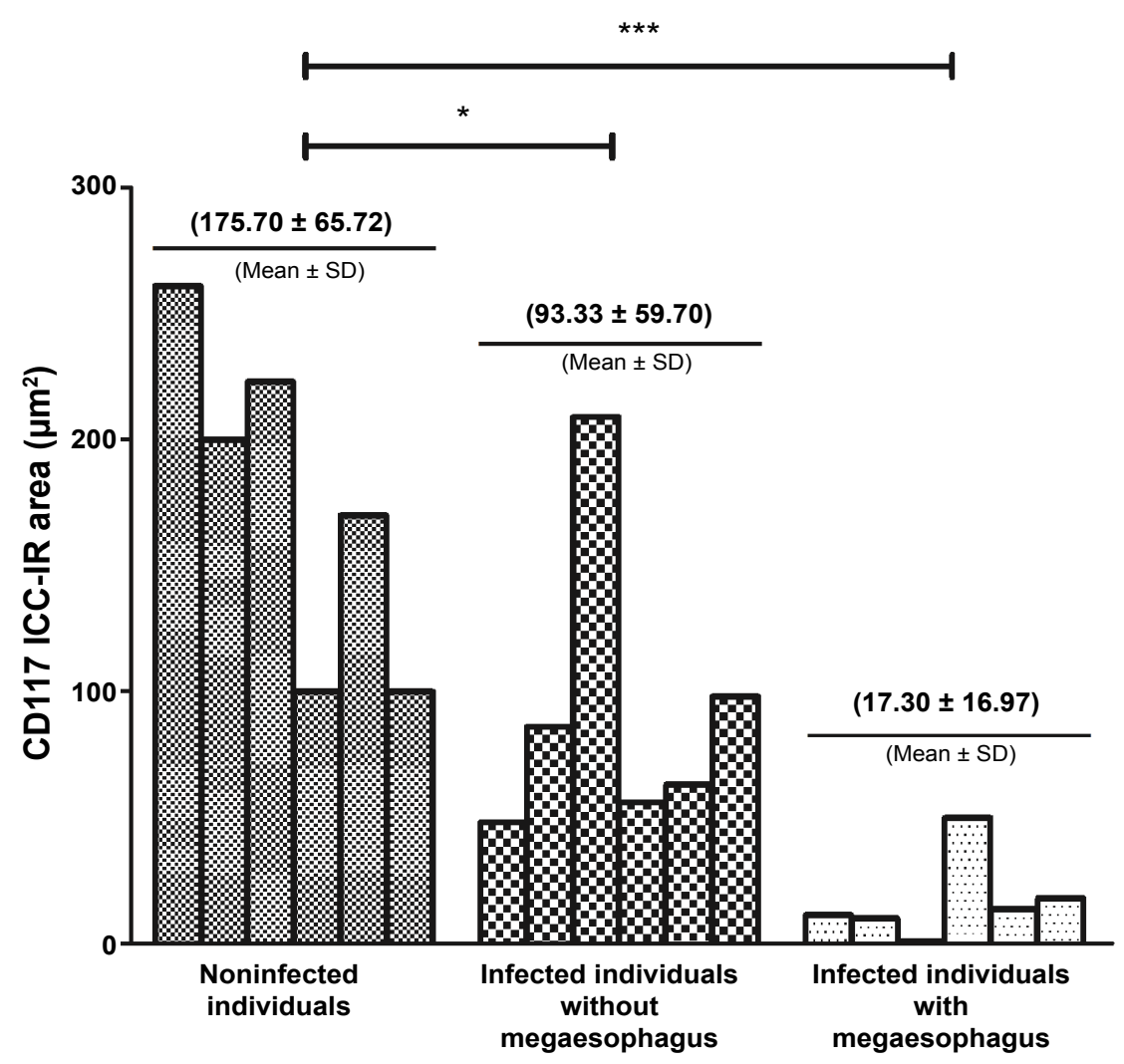

Figure 4: Morphometric analysis of the CD117 ICC-IR area in the inner muscle layer of esophagus from noninfected individuals and infected individuals, with and without megaesophagus. The bars express individual values and the mean \pm SD is presented above each group.

"Statistically significant differences between the noninfected individuals and infected individuals without megaesophagus were observed $(p<0.05)$.

${ }^{* * *}$ Statistically significant differences between the noninfected individuals and infected individuals with megaesophagus were observed $(p<0.001)$.

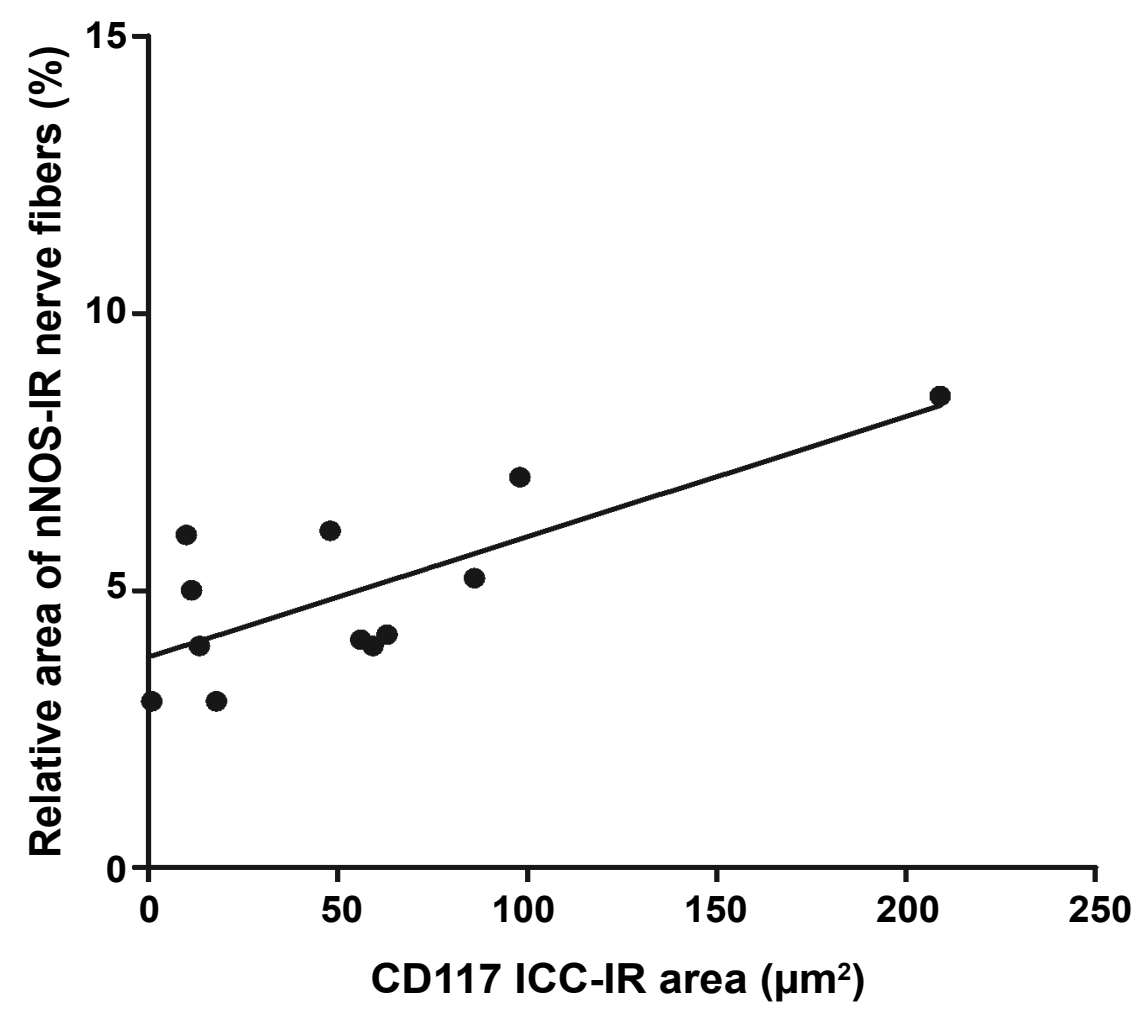

Figure 5: Correlation analysis between relative area of nNOS-IR nerve fibers and CD117 ICC-IR area in esophagus from $T$. cruzi infected individuals with and without megaesophagus $(r=0.7567$ and $p=0.0044)$. 
production of NO by these neurons and the transmission of this NO to the muscle of the gastrointestinal tract, is necessary for sphincter relaxation. This process allows for the passage of gut contents and is essential for muscle relaxation during peristalsis [14,15]. Decreased nitrergic innervation has been observed in idiopathic achalasia (inability of the sphincter to relax) and is considered an important factor in its pathogenesis [21-22]. Here, we found decreased nitrergic innervation in infected individuals with megaesophagus. Previous studies have demonstrated the presence of achalasia in almost $100 \%$ of chagasic individuals with megaesophagus and also in some asymptomatic $T$. cruzi infected individuals $[27,28]$. Here, we demonstrated that a subgroup of individuals infected without megaesophagus also have a loss of nitrergic nerve fibers in the lower esophagus. Therefore, it is possible that the reduction of nitrergic innervation in $T$. cruzi infected individuals contributes to the failure of peristalsis and to the inability of the sphincter to relax. Unfortunately, due to the lack of manometric study data and dysphasia complaints within our group, it is not possible to evaluate this hypothesis at this time.

Regarding the analyses of the ICCs, reduced CD117-immunostained areas were observed in the inner muscular layer of the esophagus from infected individuals with megaesophagus, confirming the results from a previous study [23]. One novel finding was the observed decrease in CD117 immuno-staining in individuals infected without megaesophagus. Because these individuals had the initial or the mild form of digestive disease, we propose that the loss of ICCs happens early in the digestive disease before dilation of organ. In the GI tract, ICCs in the inner muscle are thought to mediate neurotransmission between enteric neurons and smooth muscle cells. The ICCs receive neuronal input and subsequently stimulate the smooth muscle cells [18]. Morphological studies corroborate this hypothesis and have shown that within the inner muscle of the GI tract, ICCs are physically interposed between varicosities of nerve endings and adjacent smooth muscle fibers. ICCS both establish synaptic contacts with neurons and form gap junctions with smooth muscle cells and the ICC-to-ICC interactions facilitate neurotransmission $[29,30]$. Thus, it is tempting to speculate that during early chronic $T$. cruzi infection, the loss of ICCs can lead to motility alterations and disturbances of sphincter relaxation and, consequently, can contribute to the development of megaesophagus.

The question of whether the loss of ICCS during $T$. cruzi infection is primarily caused by the accelerated death of mature cells or by the impaired regeneration of these cells was not addressed in this study. It is well known that, like other cells, the number of ICCs is controlled by several factors that regulate proliferation and death and that ICCs continuously undergo apoptosis in the GI tract of healthy individuals [12-31]. Because neurons produce Stem Cell Factor (SCF), which activates the c-kit receptor and stimulates the proliferation, survival and differentiation of ICCs [32], the denervation process may be one of multiple causal factors that lead to ICCS loss in the esophagus of T. cruzi infected individuals.

An interesting observation in this study was that CD117-IR ICC area in T. cruzi infected individuals positively correlates with the relative area of nNOS-IR nerve fibers. Although data from correlation analyses should not be interpreted as causative, those data in conjunction with data from previous studies suggest that alterations in both nitrergic innervation and ICC density may be viewed as inter-dependent events. A decrease in ICCS density in the muscle layers has been associated with reduction of the NO-dependent inhibitory response [33] and several other studies in the literature have implicated ICCs in NO-dependent neurotransmission $[11,18,29,34]$. Moreover, NO is considered to be a cytoprotective molecule that affects the survival of the ICCs $[35,36]$.

\section{Conclusion}

In conclusion, this study of individuals with Chagas disease suggests that the loss of nitrergic innervation and ICCS may be implicated in the development of megaesophagus. Furthermore, our data, which are consistent with data from previous studies, show the inter-dependence between nitrergic innervation and ICCs and suggest the importance of continuing these investigations. Future studies, employing a combination of clinical and pathological research will be essential in furthering our understanding of the natural history of Chagas disease.

\section{References}

1. World Health Organization (2017) Chagas disease (American trypanosomiasis).

2. Pérez-Molina JA, Molina I (2017) Chagas disease. Lancet.

3. Matsuda NM, Miller SM, Evora PR (2009) The chronic gastrointestinal manifestations of Chagas disease. Clinics (Sao Paulo) 64: 1219-1224.

4. Pinazo MJ, Lacima G, Elizalde JI, Posada EJ, Gimeno F, et al. (2014) Characterization of digestive involvement in patients with chronic T. cruzi infection in Barcelona, Spain. PLoS Negl Trop Dis 8: e3105.

5. Nascimento RD, de Souza Lisboa A, Fujiwara RT, de Freitas MA, Adad SJ, et al. (2010) Characterization of enteroglial cells and denervation process in chagasic patients with and without megaoesophagus. Hum Pathol 41: 528-534.

6. Nascimento RD, Martins PR, de Souza Lisboa A, Adad SJ, Morais da Silveira AB, et al. (2013) An imbalance between substance $P$ and vasoactive intestinal polypeptide might contribute to the immunopathology of megaesophagus after Trypanosoma cruzi infection. Hum Pathol 44: 269-276.

7. Köberle F (1968) Chagas' disease and Chagas' syndromes: The pathology of American trypanosomiasis. Adv Parasitol 6: 63-116.

8. Andrade ZA, Andrade SG (1969) Immunochemical study of experimental Chagas' disease. Rev Inst Med Trop Sao Paulo 11: 44-47. 
9. Adad SJ, Andrade DC, Lopes ER, Chapadeiro E (1991) Pathological anatomy of chagasic megaesophagus. Rev Inst Med Trop Sao Paulo 33: 443-450.

10. Farrugia G (2008) Interstitial cells of Cajal in health and disease. Neurogastroenterology Motil 20: 54-63.

11. Groneberg D, Zizer E, Lies B, Seidler B, Wagner M, et al (2015) Dominant role of interstitial cells of Cajal in nitrergic relaxation of murine lower oesophageal sphincter. J Physiol 593: 403-414.

12. Kwon YH, Kim N, Nam RH, Park JH, Lee SM, et al. (2017) Change in the interstitial cells of Cajal and nNOS positive neuronal cells with aging in the stomach of F344 Rats. PLoS One 12: e0169113.

13. Guo T, Li J, Li J, Kong D, Bi C, et al. (2017) Association between hyperpolarization-activated channel in interstitial cells of Cajal and gastrointestinal dysmotility induced by malignant ascites. Oncol Lett 13: 1601-1608.

14. Yamato S, Saha JK, Goyal RK (1992) Role of nitric oxide in lower esophageal sphincter relaxation to swallowing. Life Sci 50: 1263-1272.

15. Sivarao DV, Mashimo HL, Thatte HS, Goyal RK (2001) Lower esophageal sphincter is achalasic in nNOS(-/-) and hypotensive in W/W(v) mutant mice. Gastroenterology 121: 34-42.

16. Huizinga JD, Thuneberg L, Kluppel M, Malysz J, Milkkelsen HB, et al. (1995) W/Kit gene required for interstitial cells of Cajal and for intestinal pacemaker activity. Nature 373: 347-349.

17. Wei R, Parsons SP, Huizinga JD (2017) Network properties of interstitial cells of Cajal affect intestinal pacemaker activity and motor patterns, according to a mathematical model of weakly coupled oscillators. Exp Physiol 102: 329-346.

18. Farré $R$, Wang $X Y$, Vidal $E$, Domènech $A$, Pumarola $M$, et al. (2007) Interstitial cells of Cajal and neuromuscular transmission in the rat lower oesophageal sphincter. Neurogastroenterology Motil 19: 484-496.

19. Müller M, Colcus S, Drescher DG, Eckardt AJ, von Pein H, et al. (2014) Murine genetic deficiency of neuronal nitric oxide synthase (nNOS(-/-)) and interstitial cells of Cajal (W/W(v)): Implications for achalasia? J Gastroenterol Hepatol 29: 18001807.

20. McCann CJ, Cooper JE, Natarajan D, Jevans B, Burnett LE, et al. (2017) Transplantation of enteric nervous system stem cells rescues nitric oxide synthase deficient mouse colon. Nat Commun 8: 15937.

21. Chen JH, Wang XY, Liu LW, Yu W, Yu Y, et al. (2013) On the origin of rhythmic contractile activity of the esophagus in early achalasia, a clinical case study. Front Neurosci 7: 77.

22. Gockel I, Bohl JR, Eckardt VF, Junginger T (2008) Reduction of interstitial cells of Cajal (ICC) associated with neuronal nitric oxide synthase (n-NOS) in patients with achalasia. Am J Gastroenterol 103: 856-864.
23. de Lima MA, Cabrine-Santos M, Tavares MG, Gerolin GP, Lages-Silva E, et al. (2008) Interstitial cells of Cajal in chagasic megaoesophagus. Ann Diagn Pathol 12: 271-274.

24. Jabari S, da Silveira AB, de Oliveira EC, Quint K, Wirries A, et al. (2013) Interstitial cells of Cajal: Crucial for the development of megacolon in human Chagas' disease? Colorectal Dis 15: e592-e598.

25. da Silveira AB, D'Avila Reis D, de Oliveira EC, Neto SG, Luquetti $A O$, et al. (2007) Neurochemical coding of the enteric nervous system in chagasic patients with megacolon. Dig Dis Sci 52: 2877-2883.

26. Garrity MM, Gibbons SJ, Smyrk TC, Vanderwinden JM, Gomez-Pinilla PJ, et al. (2009) Diagnostic challenges of motility disorders: Optimal detection of CD117+ intersticial cells of Cajal. Histopathology 54: 286-294.

27. Andrade CG, Cecconello I, Nasi A, Zilberstein B, Filho JR, et al. (2006) Lower esophageal sphincter analysis using computerized manometry in patients with chagasic megaesophagus. Dis Esophagus 19: 31-35.

28. Silva LC, Vicentine FP, Herbella FA (2012) High resolution manometric findings in patients with Chagas' disease esophagopathy. Asian Pac J Trop Med 5: 110-112.

29. lino S, Horiguchi K, Nojyo Y, Ward SM, Sanders KM (2009) Interstitial cells of Cajal contain signalling molecules for transduction of nitrergic stimulation in guinea pig caecum. Neurogastroenterology Motil 21: 542-550, e12-e13.

30. Cobine CA, Hennig GW, Kurahashi M, Sanders KM, Ward SM, et al. (2011) Relationship between interstitial cells of Cajal, fibroblast-like cells and inhibitory motor nerves in the internal anal sphincter. Cell Tissue Res 344: 17-30.

31. lantorno G, Bassott G, Kogan Z, Lumi CM, Cabanne AM, et al. (2007) The enteric nervous system in chagasic and idiopathic megacolon. Am J Surg Pathol 31: 460-468.

32. Huizinga JD, Reed DE, Berezin I, Wang XY, Valdez DT, et al. (2008) Survival dependency of intramuscular ICC on vagal afferent nerves in the cat esophagus. Am J Physiol Regul Integr Comp Physiol 294: 302-310.

33. Villanacci V, Annese V, Cuttitta A, Fisogni S, Scaramuzzi G, et al. (2010) An immunohistochemical study of the myenteric plexus in idiopathic achalasia. J Clin Gastroenterol 44: 407410.

34. Ward SM, Morris G, Reese L, Wang XY, Sanders KM (1998) Interstitial cells of Cajal mediate enteric neurotransmission in the lower esophageal and pyloric sphincters. Gastroenterology 115: 314-329.

35. Choi KM, Gibbons SJ, Roeder JL, Lurken MS, Zhu J, et al. (2007) Regulation of interstitial cells of Cajal in the mouse gastric body by neuronal nitric oxide. Neurogastroenterology Motil 19: 585-595.

36. Vermeiren J, Hindryckx P, Van Nieuwenhuyse G, Laukens D, De Vos M, et al. (2012) Intrarectal nitric oxide administration prevents cellular infiltration but not colonic injury during dextran sodium sulfate colitis. Dig Dis Sci 57: 1832-1837. 